\title{
Current trends in building defects relating to the fabric of a building, its cladding and structure
}

Received (in revised form): 14th December, 2004

\section{Andrew Tee}

is Technical Director of CNP Ltd. Previously he was Head of the Building Engineering and Technology Group at Watts and Partners and prior to this, a Director of Quest Technical Services. $\mathrm{He}$ is a chartered engineer specialising in building defect analysis and specialist investigations associated with structure, curtain walling and cladding, general fabric defects and deleterious materials. A particular focus of his work is the presentation of often complex technical issues in a concise and commercial manner. Much of his work during the past ten years has been for building surveyor or investor/developer clients.

He has acted as Expert Witness in matters relating to built-up roofing, dampness, condensation problems, general fabric disrepair and woodwool slab shuttering. He has also lectured widely at in-house training seminars to building surveyors, at CIRIA and Henry Stewart Conferences, and the Building Surveyors National Conference.

\begin{abstract}
This paper is an update on many commonly known and established building defects where there may be a new view or revised thinking. It is also an update on new construction and the particular defects that may occur. The topics covered here are not necessarily an exhaustive list of all present-day problems with either existing or new buildings, it is merely a summary of those issues that appear to be particularly topical. These notes particularly relate to defects with commercial buildings as it is the author's experience that there appears to be more change in this field compared to residential properties. The paper is presented as a series of problems relating to the fabric of a building, its cladding and structure.
\end{abstract}

\section{Keywords:}

steel-frame corrosion, composite cladding, cladding interfaces, rainscreen cladding, curtain walling stick systems, nickel sulphide, solar-glazing films, floor vibration, hollow-pot floors, woodwool, industrial slabs, multi-storey car parks, HAC, concrete problems

\section{FABRIC PROBLEMS}

Andrew Tee CNP Ltd

Warwick House, Claremont Lane Esher KT10 9DP, UK

Tel: +44 (o) 1372466445

Fax: +44 (o) 1372466332

E-mail: andrew.tee@cnpltd.co.uk

\section{Steel-frame corrosion}

'Regent's Street Disease' is the commonly used term loosely applied to the corrosion of steel framework and the consequent disruption to masonry/stone façades where they are built tight to the steelwork. 
Regent's Street Disease is common to steel-frame buildings constructed in the 1920s and 1930s.

Corrosion of steelwork is an electrical chemical process set up on the surface of the steel by contact with either other metals or usually by local variations in the steel itself. An electrical chemical cell is formed with an anodic cell, which corrodes, and a cathodic cell, which is protected. The corrosion cell is completed by an electrolyte, ie moisture, allowing the flow of positively and negatively charged ions.

As rust forms on the surface of steel, it becomes cathodic, thus inducing the remaining steel to corrode as an anode. Rust typically occupies a volume approximately $8-10$ times greater than the consequent loss from the original steel section. The expansive formation of rust results in an outwards force being applied to any brickwork or concrete surrounding the area of steel corrosion. Quite often the corrosion site and consequent disruption are localised.

With steel frame corrosion, the presence of moisture trapped between the steelwork and masonry, together with air permeability through the masonry façade, may be sufficient to instigate steel corrosion. It is important to note, however, that the onset of corrosion commences when it is obscured from view behind the façade. It is not until a moderately advanced stage of corrosion that visible stress to the façade occurs. For many steel-frame buildings, this point is reached at an age in the order of approximately 60 years. The extent of corrosion and subsequent formation of expansive rust deposits ultimately may be sufficient to cause cracking and outwards movement of a masonry façade.

The traditional repair for steel frame corrosion involves the removal of visually defective masonry, the treatment of all corrosion-affected steelwork and the subsequent replacement of masonry either with existing or new. Such an approach is extremely time-consuming and consequently particularly expensive.

There is a modern alternative to traditional repair and that is cathodic protection (CP). At the present time (the end of 2004), CP systems have been installed as a remedial solution to a small number of façades with steel frame corrosion. CP has, however, been used successfully for the repair of in situ reinforced concrete civil engineering and building structures for many years.

$\mathrm{CP}$ effectively reverses the electrical chemical process. It involves the flow of an electrical current in solution from the anode to the cathode. $\mathrm{CP}$ effectively reverses the current flow by implanting sacrificial anodes within the façade which corrode in preference to the embedded steelwork which then becomes cathodic. CP involves the installation of sacrificial anodes within the masonry bed joints and does not entail the removal of masonry; however, any cracked or displaced masonry will need to be repaired using conventional traditional repair methods. The early typical problems with adapting $\mathrm{CP}$ for use on steel-framed buildings have largely now been overcome and $\mathrm{CP}$ as a technique is proven in that it will stop any further corrosion.

Owners of buildings at risk of corrosion, and building owners who are concerned with regard to the long-term durability of façades, may find the 
introduction of a CP scheme particularly attractive. The initial set-up and installation costs are high but these costs may be easily offset many times over by the anticipated saving of undertaking traditional repairs over a long period of time. It is on those buildings where clients are taking a long-term view of their durability that $\mathrm{CP}$ has been installed.

Under normal occupational leases, the landlord may have difficulty recovering the cost of $\mathrm{CP}$ from a tenant as it could be classified as an improvement rather than repair.

\section{Composite cladding}

The performance of composite cladding panels in fire is a concern for building insurers. Consequently, there may be a reluctance to provide cover at reasonable commercial rates. Composite cladding panels are a factory manufactured product comprising an outer and inner coated metal panel adhesively bonded to an inner core of insulation. They may be used externally as wall and/or roof cladding, or internally as a compartment wall or partition.

For external roof and wall cladding, 90 per cent of panels utilise an inner core of either polyurethane (PUR) or polyisocyanurate (PIR). For internal wall and partition applications, particularly in situations such as food processing plants, cold storage facilities etc, expanded polystyrene (EPS) is most popular; however, PUR, PIR and mineral wool, among other materials, is used. It is the performance of some of these insulant materials in a fire which is of potential concern.

Combustibility and fire spread is of greatest concern, particularly the performance of EPS which as a thermoplastic material burns, shrinks and melts in a fire. Voidage between the outer and inner sheets can result in rapid fire spread. PUR will undergo surface burning and localised charring. Shrinkage can lead to delamination of panels. PIR shows less tendancy to burn.

Instability of the panel facings is also an issue where there is no proper support or restraint. For roof and wall cladding, the outer and inner sheets are tied together by purlins and sheeting rails to prevent detachment. However, the greatest concern relates to internal compartment walls constructed with an EPS core, often of thickness $200 \mathrm{~mm}$ or more, where there is a greater risk of delamination as the panel restraint usually relies on the EPS itself rather than on any additional support. These panels can collapse very quickly in a fire and consequently pose the greatest risk to fire fighters.

LPS 1181 is a test sanctioned by the LPC and BRE to evaluate the performance of a composite panel in a fire. Panels meeting the LPS 1181 standard will not make a significant contribution to fire spread. LPS 1208 is the appropriate test for fire resistance of compartment walls. Panels complying with LPS 1181 or LPS 1208 should be used for new buildings or replacement claddings. In particular, panels that are LPC approved to LPS 1181 may be classified as non-combustible although the insulant material itself may be combustible. Many manufacturers supply visually similar LPC compliant and non-compliant branded panels.

EPS and the majority of PUR insulation materials will not be LPC approved. It is often very difficult to assess the difference between PIR or 
PUR; however, in the absence of information to the contrary, it should be assumed that the material is non-approved PUR. Although PUR panels may be considered to be combustible, they may not contribute to fire spread.

While EPS and PIR/PUR-type insulation may be visually identified after cutting through the panel facings, the difference between PIR and PUR insulation requires laboratory infra-red analysis of a sample for verification. Alternatively, the original manufacturer may be able to provide the necessary confirmation, if they can be traced.

A surveyor should attempt to identify the type of core insulation for suspect composite panels, paying particular attention to compartment walls. It is essential that the use of composite panels is drawn to the attention of the building insurers. (For further reading, refer to the Association of British Insurers' Technical Briefing publication entitled 'Fire Performance of Sandwich Panel Systems'.)

\section{CLADDING PROBLEMS}

\section{Interface problems}

\section{Robust trim details}

\section{Interface problems}

Modern curtain walling systems comprise the use of traditional site-assembled stick systems or factory-assembled unitised/panellised systems. The design of the systems nowadays is to a high standard. The site-assembled stick systems to some extent are sensitive to poor site workmanship, while the factory-assembled unitised and panellised systems have a very high standard of component workmanship.

Despite the high standard of design and manufacture of these elements, there is often poor coordination between the sub-contractors responsible for various types of cladding, ie the interface between curtain walling, rainscreen panels and stonework. Often each of these cladding treatments is designed in concept by a single architect, however, the interface detailing is left to the individual sub-contractors and our experience here is that coordination is often lacking. The result of this lack of coordination is that there is often a lack of fit between adjacent component parts and/or irregular joint widths, which are particularly aesthetically unattractive. In the worst cases of poor fit and poor detailing, this may result in water ingress and/or excessive air permeability. Therefore it should not be assumed that modern curtain walling and rainscreen panelling are likely to be defect free. The focus of attention should be the peripheral edges of the installations.

\section{Robust trim details}

Some systems include decorative metal trims as an aesthetic feature. Usually the principal component parts of a unitised system are factoryassembled to a high standard; however, decorative component parts are sometimes site-fitted and the fixings of these components are occasionally not as durable as the principal component itself. We have witnessed the clip fitting of aluminium trim panels to high-rise office buildings where the clip-fitted trims are subject to accidental damage from window cleaning cradles and may also be jettisoned by high winds. Again the robust fitting of decorative trims is a particular point to consider with new installations. 


\section{Rainscreen backing membrane}

\section{Site-assembled stick systems}

\section{Rainscreen backing membrane}

Rainscreen cladding, as a principle, is a tried and tested method of preventing water ingress through a façade. On many modern buildings, rainscreen panels are commonly decoratively treated panels of aluminium, mechanically fixed to support brackets, which in turn are fixed to the main structure.

Rainscreen installation relies on a watertight membrane installed behind the rainscreen panel and often proprietary, single-ply, elastomeric membranes are used for this purpose. These materials are inherently durable, particularly in rainscreen cladding installations where they are hidden from weathering and damage. The method of fixing the panel necessitates that the support brackets penetrate the membrane through the structure. Each of these brackets must be sealed weather-tight and these, in our experience, prove to be troublesome and difficult to detail such that they cannot be sealed on site to a satisfactory standard of workmanship. We consider that fixing brackets penetrating the rainscreen membrane in this way is a particularly common design detail and weak link of rainscreen cladding and an issue to consider during a survey.

\section{Site-assembled stick systems}

Site-assembled stick systems have their own particular problems. For many years they remained the most popular type of curtain walling installation based on their relative simplicity and acceptable cost. For prestige buildings, it is now more commonplace for unitised or panellised systems to be used offering the architect a bespoke, aesthetically pleasing façade.

Stick systems comprise a site-assembled arrangement of aluminium box section mullions and transoms supporting double-glazed vision units and, most often, double-glazed spandrel panels. The double-glazed units are retained within the stick system by dry gaskets and aluminium pressure plates and the system is designed to be pressure equalised and internally drained. Most modern systems work on the principle that a small amount of rainwater may pass the outer gaskets and then harmlessly drain via the transoms or the mullions without penetrating the inner gaskets. The systems rely on the principle of pressure equalisation, which prevents negative pressures within the glazing rebate chambers from effectively 'sucking' water through the inner gaskets.

Earlier site-applied stick systems were sealant intensive and particularly workmanship sensitive, requiring each of the joints between the mullions and transoms to be sealed on site to prevent internal air permeability. Improved modern systems are more tolerant of poor on-site workmanship but nevertheless poor site assembly of the systems remains commonplace and it is often found that the jointing systems are incorrectly fitted resulting in poor weather-tight performance. Unfortunately, any deficiencies with the installation of a stick system may be identified only upon removal of the decorative cover caps and the pressure plates, which is often a task for a specialist cladding consultant. 


\section{Nickel sulphide}

\section{Nickel sulphide}

Failure of toughened glass installations may occur as a consequence of nickel sulphide inclusions. These typically spontaneous failures may be attributable to nickel sulphide inclusions, but it is important to note that other factors such as edge damage or handling damage of the glass may be a contributory cause.

The process of toughening glass creates small crystals of nickel sulphide which may become unstable. When heated during thermal gain, and over time, a volume expansion of the nickel sulphide crystals may cause spontaneous failure. All glass has some nickel sulphide inclusions present, however, only those inclusions which are sufficiently large enough and contained within the tension zone of the glass will result in failure.

Failures associated with nickel sulphide inclusions exhibit a characteristic pattern of cracking, containing the inclusion itself, immediately surrounded by two small 'butterfly' shaped fragments of glass. If the inclusion can be salvaged, then laboratory optical microscopy analysis may confirm the presence of a nickel sulphide inclusion; however, quite often all of the glass pane will fall out of the frame, thus restricting identification. Generally most failures occur within an initial period of one year after manufacture, with a peak at approximately five years thereafter. The frequency then decreases; however, fractures have occurred more than 20 years after the installation of glass. Nickel sulphide inclusions historically have been a serious problem, but improvements with quality control have drastically reduced its incidence. There are concerns that these improvements lapsed during the late 1980s, evident by failures on some landmark 1990s buildings.

'Heat soak' testing is a quality controlled process whereby panels of toughened glass are subjected to accelerated elevated temperatures to stimulate the transformation of the crystals and thus initiate immediate failure. Panels with large nickel sulphide inclusions should shatter during the process, and it is though that 90 per cent or more of toughened glass failures will occur. The heat soak test could be used either as a sampling method or as an additional treatment, which in the case of clear toughened glass could add up to 20 per cent to the cost. Heat soaking does not change any of the physical properties of toughened glass and therefore there is no means of visually checking if this process has been carried out.

Annealed glass and heat strengthened glass is not affected by nickel sulphide inclusions. The compressive stresses within toughened glass is a contributory cause of spontaneous failure. Other than in-service bending, there are no compressive stresses in annealed glass. Compressive stresses occur within heat strengthened glass, or partially toughened glass, although the magnitude of the stresses is not high enough to cause failure from nickel sulphide inclusions.

Failure of toughened glass, as a consequence of nickel sulphide inclusions, is a rare occurrence but should, nevertheless, be assessed during a building survey. It is essential that all toughened glass is heat 
Solar-glazing films soak tested to significantly reduce the likelihood of failure. For new buildings, construction records may be available to verify this. For installations, where failure is unacceptable, alternatives such as laminated glass should be considered.

\section{Internal solar-glazing films}

There is a trend these days to improve the solar performance of existing double-glazed unit installations by applying a solar-reflective glazing film on the internal face of double-glazed units. The potential problem with applying a solar-reflective film internally is that the inner pane of glass may suffer from premature stress fracture and failure.

All types of glass absorb some energy when exposed to solar radiation. This results in a rise in the glass temperature. At the same time, the edges of the glass, which are shaded from direct sun by the glazing rebate, will have a lower temperature. The ability of glass to resist solar-thermal energy and not break is determined by the glass edge strength. The glass edge strength depends upon its size, the type of glass, its thickness and the condition of the edge of the glass. The larger and thicker the pane of glass, the weaker its thermal edge strength. Double glazing also increases the stress upon the inner pane as the outer pane reduces the inner pane's ability to release the absorbed heat. A number of other features affect the stress in the pane, such as blinds and external overhanging shading.

As solar films change the thermal characteristics of a pane of glass, a thermal stress analysis should be undertaken to assess if the application of a certain solar film will be suitable for a glazing configuration or represent the threat of failure of units through thermal shock fractures. The type of glass usually at risk is either annealed glass or laminated glass. Toughened and heat-strengthened glass panes are not affected in this way. Glass panes in excess of $4.5 \mathrm{~m}^{2}$ and of a thickness greater than $9 \mathrm{~mm}$ are also at a higher risk.

A thermal risk analysis should be undertaken by a prospective supplier to take into account the reflections, absorption and transmittent factors of the film as certain films will be suitable for a glazing configuration while certain films will not. The analysis should also take into account whether the glazing is tinted, clear, double or single glazed. Despite the reassurance that such a thermal risk analysis may give, there is also the slight risk that premature failure may still occur if there are edge defects with the glass that are currently hidden from view behind the glazing rebate. Guarantees offered by manufacturers are often limited solely to the performance of the film itself and some do not provide a guarantee for glass breakage. A cautious approach is therefore required for specifying solar-glazing films on the inside of large panes of thick annealed or laminated glass.

\section{STRUCTURAL PROBLEMS}

\section{Vibration of modern composite steel floors}

The structure of many commercial buildings comprises the use of structural steel frames with floor beams acting compositely with 
lightweight concrete floor slabs cast on a profiled metal deck permanent shutter. Composite floor structures of this type are highly efficient structurally and have relatively low mass. Problems have been encountered with vibrations in this type of flooring due to the low natural frequency of the system, which have led to perceptible dynamic responses under normal footfall traffic. This effect is now controlled in the design of modern structures where the floor should be designed for natural frequency of not less than $4 \mathrm{~Hz}$. This criterion is generally sufficient to reduce vibrations to acceptable levels for office accommodation where computer screens are used.

Problems with steel vibration are very rare but have occurred and, if an end user is particularly sensitive to floor vibrations for computer VDU use, this may be an issue. Special precautions are necessary for hospital floors, particularly those in operating theatres, or other sensitive areas.

\section{Hollow-pot ribbed floors}

The use of hollow-pot ribbed floors is of particular interest in the context of poor compaction of the concrete and subsequent defects to the soffit of the ribs which contain reinforcement. Hollow-pot floors comprise in situ reinforced concrete ribs at close centres infilled with clay hollow pots. The ribs and pots are overlaid with a monolithically cast, integral, reinforced concrete topping which forms part of the structural floor. Occasionally the soffit of the in situ concrete rib is concealed above a clay slip tile.

Problems with poor compaction of the concrete at the time of construction may result in voidage of the concrete in and around the reinforcement at the base of the ribs. If the soffit of the rib is concealed above the clay tile then this defect will be obscured from view.

The result of voidage may reduce the fire resistance where the protective concrete cover may be lost and, in particularly damp conditions, say at roof level, reinforcement corrosion durability may also be reduced. The structural strength of the floor construction is reduced only in the most severe cases of concrete voidage. If the extent of voidage is not severe then repair only may be required to replace the fire resistance and durability. In this case, hand-placed concrete repairs using a proprietary cementitious mortar may be acceptable. In the small number of cases where a structural repair is required, the application of sprayed 'Gunite' concrete is necessary.

\section{Woodwool slabs}

Woodwool slabs remain on the list of deleterious materials on the basis that poor compaction of the concrete at the time of construction may result in loss of grout and consequent honeycombing of the concrete around the reinforcement at the soffit of a slab or rib. The relevant point to note with woodwool slabs is that the defects associated with their use may be similar to any type of ribbed floor such as a hollow-pot floor previously described. Voidage of concrete at the base of the rib equally may occur with a woodwool slab as with a clay hollow pot. Loss of grout and subsequent honeycombing are usually attributable to the use of woodwool slabs rather than clay hollow-pot floors. With woodwool slabs the grout loss occurs in 
the open texture of the woodwool itself. Defects associated with woodwool slabs have a similar effect in that they may reduce the fire-resistance and corrosion durability and may, in the most extreme cases, reduce structural strength. Fire resistance may be reinstated by the addition of plaster or boarding; however, the fire resistance of the woodwool itself, albeit minimal, should not be ignored. Remedies for structural deficiencies are similar to those used for clay hollow-pot floors.

\section{Industrial ground-floor slabs}

The design and construction methods associated with industrial groundfloor slabs have improved considerably over the years. Best practice guidance is contained within the Concrete Society Report No. 34 entitled 'Concrete Industrial Ground Floors' (Concrete Society, 2003). At the launch seminar of this publication in 2003, a cross-section of end users unanimously reported that the single biggest problem they encountered with industrial warehousing was the quality of the concrete slabs and, in particular, failure of joints and slab cracking. The most common defect associated with the construction of concrete warehouse floors is uncontrolled drying shrinkage and subsequent cracking. Modern design methods to combat this problem, as outlined in Report No. 34 (Concrete Society, 2003), include various construction techniques and different joint details.

Historically, most ground-floor slabs were cast using the long-strip method by which individual long strips of concrete slab were cast alternately in widths of up to $5 \mathrm{~m}$. The slabs were cast alternately leaving an open bay between adjacent cast slabs. After sufficient time for each strip to cure and shrink, the intermediate infill strips were cast. This form of construction is still used, particularly where a high-tolerance surface finish is required.

The more modern technique of casting a slab in large bays is often utilised to reduce costs and to reduce the number of construction joints. The trade-off of this type of construction is that surface tolerance in terms of level and flatness is often of a lower standard compared to the long-strip method. Despite employing best practice design, shrinkage cracking still occurs and relatively new slabs often suffer from a significant quantity of cracking. Indeed, the author has knowledge of one particular warehouse, no more than three years' old, where defects associated with slab cracking have necessitated wholesale replacement of the slab.

Of course, these are particularly rare cases. Things to look out for in designs include the use of a damp-proof membrane acting not only as a waterproof membrane but also as a slip membrane between the underside of the slab and the top of the sub-base. This is essential to allow unrestrained shrinkage movement of the slab. The use of dowelled joints needs to be carefully controlled on the basis that if they are not installed and aligned correctly they may cause the joint to lock-up, thus preventing shrinkage movement. It is worth noting that end users are becoming particularly more demanding, often requiring high-tolerance surface finishes for laser-guided fork-lift trucks. 
Joints are an unavoidable element in all concrete floors and their design and construction require careful attention because they can be a significant potential source of problems. The edges of slab panels are vulnerable to damage caused by fork-lift truck movements with wider joints being more susceptible. The small, hard wheels of pallet trucks and similar vehicles are particularly aggressive. Owners and users of industrial warehouses should include the floor joints and sealants in any programme of routine monitoring and maintenance. Joints should be inspected routinely and remedial action taken when a failure has occurred. If repairs are not carried out, the joint sealant, arris and surrounding floor will deteriorate further. Despite the often onerous serviceable condition of joints, they remain a potential weak link.

\section{Multi-storey car parks}

Following the collapse of the Pipers Row car park in 1997, a number of investigations and assessments have been undertaken by the Health and Safety Executive (HSE) and also by the Institution of Civil Engineers and Institution of Structural Engineers. On the night of 20th March, 1997, a 120-tonne section of the top deck of the Pipers Row multi-storey car park collapsed. Although open, the car park was unoccupied and no one was injured. Pipers Row car park was a flat-slab structure designed and built in 1964 using a technique called 'lift slab'. It was believed to be the first lift-slab structure to have failed in service. Research was commissioned following concerns about car parks built using the lift-slab technique and about the safety of all flat-slab structures subject to aggressive environments.

The research undertaken by the HSE and others concluded that, if properly maintained, the Pipers Row car park should have had a reasonable margin of strength in relation to the actual loadings imposed in use. Deterioration of the concrete over and around the column/slab zone, however, led to punching shear failure of the concrete slab. The mechanical column/slab connection, unique to the lift-slab method of construction, did not fail.

The concrete deterioration resulted from localised breakdown of the overlying waterproofing membrane. This allowed water access to areas of poor quality concrete in the upper part of the slab, leading to frost damage and loss of strength. The research also found that assessment of structural integrity of this form of lift-slab structure required cautious engineering judgement. One of the main lessons from the research was that owners of carpark structures need to have robust procedures for maintenance in place to help prevent similar collapses. The employment of people with appropriate levels of competence is also significant to ensure that these structures are properly inspected, maintained and, where necessary, repaired.

A report entitled 'Recommendations for the Inspection, Maintenance and Management of Car Park Structures' was published by the Institution of Civil Engineers in 2002 and in this document the concept of a 'life care' plan for individual multi-storey car parks was outlined, providing a chronological history of the construction and maintenance regime undertaken. A further result of the recent investigation assessment works 
has highlighted that proper maintenance of car parks, in particular, waterproofing levels on decks, is of critical importance.

\section{High alumina cement}

Much has been reported on high alumina cement (HAC) over the years and the structural use of HAC remains banned and on the list of deleterious materials. There has been ongoing debate among structural engineers about the original causes of failures of pre-cast concrete beams manufactured using HAC. These failures, which occurred in the early to mid-1970s, were attributable to conversion of HAC; however, some have recently questioned whether the defects were associated with the design and construction of pre-cast members and not necessarily a function of converted HAC. The consensus view on this appears to remain that conversion was a significant contributory factor. Nevertheless there is a small but growing call for HAC to be reintroduced as a structural material, albeit in a very carefully controlled and very specific manner. Particularly its characteristics of chemical resistance are attractive for subsurface foundation work and there is some commercial pressure being put on learned institutions and the British Standards Institution to consider its reintroduction.

It should be noted that HAC has now been rebranded as calcium alumina cement (CAC) and this should not be confused with anything other than HAC. Our experience of HAC is that no reported failure of HAC has occurred since the original problems in the early to mid-1970s and that most strength assessments of HAC undertaken have mainly concluded that there is a sufficient reserve of strength, even converted, to support the applied live loads. Where there is some deficiency, this may be addressed by either reducing the allowable liveload or by relatively simple strengthening. From an engineering and technical point of view, the existing use of HAC in building structures causes very few problems, but it remains a high priority for funders as a deleterious material.

\section{Concrete problems}

\section{Alkali silica reaction}

Alkali silica reaction (ASR) is often described very loosely as 'concrete cancer'. For ASR to occur, the three simultaneous components of a reactive aggregate, a high alkali level within the concrete and a persistent quantity of moisture are required. Fortunately, incidences of ASR in building structures are very rare and most of the small number of cases identified have been associated with civil engineering structures such as bridges.

\section{Thaumasite form of sulphate attack}

Sulphate attack on cement-based construction materials has been recognised for many years and is normally minimised in the UK by following current best practice guidance; however, since 1990 a few cases 
of a new form of sulphate attack, the thaumasite form of sulphate attack (TSA), have been discovered in buried concrete.

The deterioration of the concrete foundations of three domestic properties in the Cotswolds has been reported by the BRE and, more recently, TSA was found in the foundations of some 30-year-old motorway bridges. These foundations were constructed with good-quality concrete which had been specified in accordance with the then current guidance to cater for the perceived ground sulphate conditions.

In the light of these discoveries, an expert group on thaumasite was set up to assess the implications for existing buildings and structures. Studies by the BRE and others previously have shown that TSA is a different form of sulphate attack from the conventional form. The number of buildings and structures potentially at risk from the occurrence of TSA in the UK is considered to be small. TSA will only occur in buried concrete where all primary risk factors-including sulphates in the ground, mobile groundwater, presence of carbonate and low temperaturessimultaneously occur to a significant degree. It is emphasised that the probability of this situation occurring is considered to be low for most existing buildings and structures. TSA is therefore considered not to be a cause for concern for most building structures.

\section{CONCLUSIONS}

There is no doubt that the quality of building construction has improved since the legacy of poor construction during the 1960s and early 1970s. Neverthless, as highlighted by some of the examples in this paper, we would be complacent if we believed that modern buildings are defect free. Design standards are ever improving and there is an increasing reliance on off-site assembly to improve workmanship. There is, however, room to improve the standard of on-site workmanship and the coordination of different trades.

Older buildings also bring us some new problems in addition to those that are well known: the increasing prevalence of steel frame corrosion is a good example. Many of these problems are directly related to maintenance and moisture. Keep the moisture out, and many of the defects discussed here will be academic.

\section{References}

Concrete Society (2003) Report No. 34: Concrete Industrial Ground Floors.

Institution of Civil Engineers (2002) Recommendations for the Inspection, Maintenance and Management of Car Park Structures. 